\title{
Parkinson's disease: general features, effects of levodopa treatment and future directions
}

\author{
Marco Aurélio M. Freire ${ }^{1 *}$ and José Ronaldo Santos ${ }^{2}$ \\ Department of Biomedical Engineering, Federal University of Rio Grande do Norte, Natal, Rio Grande do Norte, Brazil \\ 2 Program of Psychobiology, Federal University of Rio Grande do Norte, Natal, Rio Grande do Norte, Brazil \\ ${ }^{*}$ Correspondence: freire.m@gmail.com
}

\section{A commentary on}

Basal ganglia circuits underlying the pathophysiology of levodopa-induced dyskinesia

by Barroso-Chinea, P., and Bezard, E. Front. Neuroanat. 4:131. doi: 10.3389/ fnana.2010.00131.

Among the neurodegenerative movement disorders, Parkinson's disease (PD) is the most prevalent (Schapira, 2009), affecting about $1 \%$ of people aged over 55 years, with a increase of fivefold by the age of 70 , characterizing aging as the most important risk factor for this pathology (Collier et al., 2007). The first description of PD was made in 1817 by the British physician James Parkinson, who described a syndrome mainly characterized by an involuntary tremulous motion, defined as a "shaking palsy" (Parkinson, 1817). Two forms of PD have been identified: a sporadic form, which affects most than $90 \%$ of all patients and whose etiology is still unknown (Tanner, 2003), and a familial form accounting for about $10 \%$ remaining, directly linked to mutations in specific genes (Dauer and Przedborski, 2003).

The main histopathological feature of PD is the loss of dopaminergic neurons of the substantia nigra pars compacta (SNpc) (Dauer and Przedborski, 2003) with a further depletion of dopamine in the striatum. Degenerating dopaminergic neurons in PD are characterized by the presence of the accumulation of cytoplasmatic inclusions named Lewy bodies, constituted by fibrillar proteins alpha-synuclein and ubiquitin (Lees et al., 2009). Following the neuronal degeneration there is a loss of the striatal dopaminergic innervation, which ultimately results in the characteristic motor dysfunction observed in PD. In addition to the motor dysfunction, cognitive, and behavioral alterations are also observed in $\mathrm{PD}$, since other neuronal groups are affected for instance in the locus coeruleus, the nucleus basalis of Meynert, and in later stages, in the neocortex (Braak et al., 2003). Although these disturbances currently do not take part in the diagnostic of PD, animal models point that they may emerge earlier than the motor disturbs (Da Cunha et al., 2001).

Though the mechanisms responsible for the loss of dopaminergic cells in PD are still unclear, there are evidences that inflammation, oxidative stress, and excitotoxicity are involved in the progression of the disease (Dawson and Dawson, 2003; Kim and Joh, 2006), albeit these events do not be specific to PD since they also contribute to other acute and chronic neurodegenerative disorders (Guimarães et al., 2009). Inflammation seems to be widely implicated to neuronal degeneration in PD because microglial cells are an important source of potentially harmful substances such as nitric oxide, free radicals, interleukin 1-beta, and tumor necrosis factor alpha (Hirsch and Hunot, 2009; LongSmith et al., 2009).

The main dysfunctions of movement affecting PD patients are bradykinesia (slowless of movement), tremor, rigidity, postural instability, and loss of motor skills (Gelb et al., 1999). One of the treatments mostly employed to alleviate these symptoms is the administration of 1-3,4dihydroxyphenylalanine (levodopa), the dopamine precursor substance. According to Olanow et al. (2004) there are two main questions related to the action of levodopa: (1) Is it toxic? (2) Its prolonged use causes motor complications? Concerning the first point, evidences point that levodopa is toxic in cell culture (Mytilineou et al., 1993), although this had not been reported on in vivo models. Regarding the later question, Barroso-Chinea and Bezard (2010) contribute with a comprehensive review in Frontiers in Neuroanatomy. In that article the authors review the gen- eral organization of the basal ganglia and focus on the abnormal disturbance of movement developed after a continuous treatment with levodopa, termed levodopa-induced dyskinesia. This phenomenon appears to be a "side effect" of the prolonged levodopa administration, though, as pointed out by the authors, some people do not develop this disturb even after several years of levodopa treatment. Why this occurs? Even with all efforts to understand the basis of the phenomenon, it still remains unclear. This dual action of levodopa can be exemplified by the control of levels of glutamic acid decarboxylase (GAD), the enzyme of synthesis of $\gamma$-amino butyric acid (GABA), in different models of PD. While some studies report a decrease of GAD expression after administration of levodopa, others, conversely, attest an increase in its expression (Barroso-Chinea and Bezard, 2010). One hypothesis is that besides of its specific action in dopaminergic neurons, levodopa could also be involved with metabolic alterations of others neuronal groups related to motor control.

Barroso-Chinea and Bezard also highlight the efforts in the development/use of imaging techniques to study the basal ganglia, which could be employed as biomarkers to, for instance, help in an early-onset diagnosis of PD or to characterize the progression of the disease. The authors cite positron emission tomography (PET) and single photon emission computed tomography (SPECT) as tools capable of provide important information regarding the events underlying the appearing/progression of the PD. In addition, animal models reproducing neuropathological/behavioral aspects of PD also are important to a better understanding of the alterations observed during this disease.

In conclusion, more studies emphasizing not only the motor deficits but also the alterations observed in areas associative 
and related to cognition can provide a more comprehensive understanding of $\mathrm{PD}$, especially correlated to the development of more effective drugs to reduce the disturbs observed in this pathology or even to a better understanding concerning the action of drugs already known.

\section{ACKNOWLEDGMENTS}

José Ronaldo Santos is a recipient of a $\mathrm{PhD}$ fellowship from Conselho Nacional de Desenvolvimento Científico e Tecnológico (CNPq) - Brazil.

\section{REFERENCES}

Barroso-Chinea, P., and Bezard, E. (2010). Basal ganglia circuits underlying the pathophysiology of levodopainduced dyskinesia. Front. Neuroanat. 4:131. doi: 10.3389/fnana.2010.00131.

Braak, H., Del Tredici, K., Rub, U., de Vos, R. A., Jansen Steur, E. N., and Braak, E. (2003). Staging of brain pathology related to sporadic Parkinson's disease. Neurobiol. Aging 24, 197-211.

Collier, T. J., Lipton, J., Daley, B. F., Palfi, S., Chu, Y., Sortwell, C., Bakay, R. A., Sladek, J. R. Jr., and Kordower, J. H. (2007). Aging-related changes in the nigrostriatal dopamine system and the response to MPTP in non-human primates: diminished compensatory mechanisms as a prelude to parkinsonism. Neurobiol. Dis. 26, 56-65.
Da Cunha, C., Gevaerd, M. S., Vital, M. A., Miyoshi, E., Andreatini, R., Silveira, R., Takahashi, R. N., and Canteras, N. S. (2001). Memory disruption in rats with nigral lesions induced by MPTP: a model for early Parkinson's disease amnesia. Behav. Brain Res. 124, 9-18.

Dauer, W., and Przedborski, S. (2003). Parkinson's disease: mechanisms and models. Neuron 39, 889-909.

Dawson, T. M., and Dawson, V. L. (2003). Molecular pathways of neurodegeneration in Parkinson's disease. Science 302, 819-822.

Gelb, D. J., Oliver, E., and Gilman, S. (1999). Diagnostic criteria for Parkinson disease. Arch. Neurol. 56, 33-39.

Guimarães, J. S., Freire, M. A. M., Lima, R. R., SouzaRodrigues, R. D., Costa, A. M., dos Santos, C. D. Picanço-Diniz, C. W., and Gomes-Leal, W. (2009). Mechanisms of secondary degeneration in the central nervous system during acute neural disorders and white matter damage. Rev. Neurol. 48 , 304-310.

Hirsch, E. C., and Hunot, S. (2009). Neuroinflammation in Parkinson's disease: a target for neuroprotection? Lancet Neurol. 8, 382-397.

Kim, Y.S., and Joh, T.H. (2006). Microglia, major player in the brain inflammation: their roles in the pathogenesis of Parkinson's disease. Exp. Mol. Med. 38, 333-347.

Lees, A. J., Hardy, J., and Revesz, T. (2009). Parkinson's disease. Lancet 373, 2055-2066.

Long-Smith, C. M., Sullivan, A. M., and Nolan, Y. M. (2009). The influence of microglia on the pathogenesis of Parkinson's disease. Prog. Neurobiol. 89 277-287.
Mytilineou, C., Han, S. K., and Cohen, G. (1993). Toxic and protective effects of L-dopa on mesencephalic cell cultures. J. Neurochem. 61, 1470-1478.

Olanow, C. W., Agid, Y., Mizuno, Y., Albanese, A., Bonuccelli, U., Damier, P., De Yebenes, J., Gershanik, O., Guttman, M., Grandas, F., Hallett, M., Hornykiewicz, O., Jenner, P., Katzenschlager, R., Langston, W. J., LeWitt, P., Melamed, E., Mena, M. A., Michel, P. P., Mytilineou, C., Obeso, J. A., Poewe, W., Quinn, N., Raisman-Vozari, R., Rajput, A. H., Rascol, O., Sampaio, C., and Stocchi, F. (2004). Levodopa in the treatment of Parkinson's disease: current controversies. Mov. Disord. 19, 997-1005.

Parkinson, J. (1817). An Essay on the Shaking Palsy. London: Whittingham and Rowland.

Schapira, A. H. (2009). Neurobiology and treatment of Parkinson's disease. Trends Pharmacol. Sci. 30, 41-47.

Tanner, C. M. (2003). Is the cause of Parkinson's disease environmental or hereditary? Evidence from twin studies. Adv. Neurol. 91, 133-142.

Received: 09 October 2010; accepted: 29 October 2010; published online: 17 November 2010

Citation: Freire MAM and Santos JR (2010) Parkinson's disease: general features, effects of levodopa treatment and future directions. Front. Neuroanat. 4:146. doi: 10.3389/ fnana.2010.00146

Copyright (ㅇ) 2010 Freire and Santos. This is an open-access article subject to an exclusive license agreement between the authors and the Frontiers Research Foundation, which permits unrestricted use, distribution, and reproduction in any medium, provided the original authors and source are credited. 